\title{
Goodbye to printed issues!
}

\author{
P. Hovenkamp ${ }^{1}$, C. Baak ${ }^{1}$
}

Published on 16 December 2016

Since the beginning of Blumea, in 1934, some 2000 articles have appeared in print (see: http://www.repository.naturalis.nl, the exact number, as usual, depending on one's definition of what constitutes an article). On the occasion of the 50th volume in 2005, Pieter Baas wrote: "Nobody can foresee how volume 100 of Blumea will look like. It will certainly be very different from the format we are used to, and which has served us so well until now".

Since then, electronic publication has become an increasingly important means of distribution and was adopted by Blumea in 2007, facilitated by Ingenta (http://www.ingentaconnect.com/ content/nhn/blumea). However, the transition to full electronic Open Access, formally achieved only one month ago, went unmarked, and was not officially announced. We do not want to let the final step in this process go similarly unnoticed.
This brief editorial therefore is to announce that this is the last issue of Blumea to appear in print. The Publisher of Blumea has decided that from volume 62 onwards, Blumea will be an e-only Open Access journal, published under a CC BY-NC-ND license. There will be no changes in focus or editorial process. The reviewing process will remain as rigorous as it was, and the formatting and layout will not change. All articles will satisfy the requirements for valid publication in the International Code of Nomenclature for algae, fungi, and plants (Melbourne Code). All articles will be available via Ingenta and will be archived and available in the Naturalis Repository (http://www.repository.naturalis.nl). Both readers and authors are encouraged to deposit articles in any other archive or repository that they have access to. It is too early to say whether this also means that we will be able to publish more than is allowed by the current limit of 300 printed pages/year.

Any queries can, and should be, directed to the Publisher of Blumea, Erik Smets (erik.smets@naturalis.nl).

\footnotetext{
${ }^{1}$ Naturalis Biodiversity Center, section Botany, P.O. Box 9517, 2300 RA Leiden, The Netherlands.
} 